\title{
Effects of blood flow restriction exercise on hemostasis: a systematic review of randomized and non-randomized trials
}

This article was published in the following Dove Medical Press journal: International Journal of General Medicine

\begin{abstract}
Dahan da Cunha Nascimento, ${ }^{1,2}$ Bernardo Petriz, ${ }^{2}$ Samuel da Cunha Oliveira,' Denis Cesar Leite Vieira, ${ }^{2,3}$ Silvana Schwerz Funghetto, ${ }^{4}$ Alessandro Oliveira Silva, ${ }^{5,6}$ Jonato Prestes'

'Graduate Program in Physical Education, Catholic University of Brasilia (UCB), Brasilia, Brazil; ${ }^{2}$ Department of Physical Education, University Center of the Federal District (UDF), Brasilia, Brazil; ${ }^{3}$ Department of Physical Education, University of Brasilia (UNB), Brasilia, Brazil; ${ }^{4}$ Department of Nursing, University of Brasilia (UNB), Brasilia, Brazil; ${ }^{5}$ Department of Medicine and Physical Education, University Center of Brasilia (UniCEUB), Brasilia, Brazil; ${ }^{6}$ Department of Medicine and Physical

Education, Integrated Colleges of the Central Plateau Educational Union (FACIPLAC), Brasilia, Brazil
\end{abstract}

\section{Video abstract}

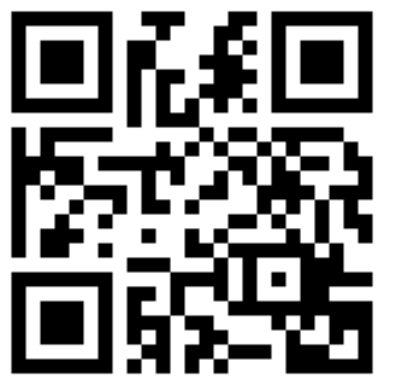

Point your SmartPhone at the code above. If you have a $Q R$ code reader the video abstract will appear. Or use: http://youtu.be/0Ljn6vAXJSE

Correspondence: Dahan da Cunha Nascimento Department of Physical Education, Catholic University of Brasilia (UCB) - Q.S. 07, Lote 0I, EPTC - Bloco G. Código Postal: 71966-700 Distrito Federal, Brasilia, Brazil

Tel +556133569000

Email dahanc@hotmail.com
Background: Blood flow restriction (BFR) exercise has shown to induce a positive influence on bone metabolism and attenuate muscle strength loss and atrophy in subjects suffering from musculoskeletal weakness. Despite the known benefits of BFR exercise, it remains unclear whether or not the pressurization of blood vessels damages the endothelial cells or increases risk for formation of thrombi. Thus, the effects of BFR exercise on coagulation, fibrinolysis, or hemostasis, remains speculative.

Objective: The aim of the present study was to perform a systematic review of the short and long- term effects of BFR exercise on blood hemostasis in healthy individuals and patients with known disease (ie, hypertension, diabetes, obesity, and ischemic heart disease).

Data Sources: A systematic review of English and non-English articles was conducted across PubMed, Science Direct, and Google Scholar databases, including reference lists of relevant papers. Study quality assessment was evaluated using the modified version of Downs and Black checklist. Search results were limited to exercise training studies investigating the effects of BFR exercise on blood hemostasis in healthy individuals and patients with disease. Level of evidence was determined according to the criteria described by Oxford Center for Evidence-Based Medicine. Study selection: Only randomized controlled trials (RCTs) and non-randomized controlled trials (NRCTs) that examined the effects of exercise with BFR exercise vs exercises without BFR on blood hemostasis in healthy individuals and patients were included.

Data extraction: Nine studies were eligible ( $\mathrm{RCT}=4$; NRCT $=5$ ).

Results: The average score on the Downs and Black checklist was 11.22. All studies were classified as having poor methodological quality wherein the level of evidence provided in all reviewed studies was level IIb only (ie, poor quality RCTs).

Conclusion: Considering the limitations in the available evidence, firm recommendations cannot be provided.

Keywords: exercise, hemostasis, vascular occlusion, blood flow restriction, coagulation system, Kaatsu training

\section{Introduction}

Blood hemostasis represents the interaction between systems controlling coagulation and fibrinolysis. It has been shown that regular exercise may positively impact the hemostatic system by balancing fibrinolytic and coagulation blood profiles in healthy individuals and patients with known diseases. ${ }^{1,2}$ Acute bouts of resistance training (RT) without blood flow restriction (BFR) in middle-aged men with coronary artery disease increased tissue plasminogen activator (tPA) and decreased plasminogen activator inhibitor-1 (PAI-1). ${ }^{3}$ These hemostatic changes decrease the risk for thrombogenesis, especially in patients with coronary artery disease. 
Thus, regular exercise may contribute to the reduction of vascular thrombotic events and protect against cardiovascular disease. ${ }^{2}$ However, the use of BFR in both healthy and diseased patients has seen a rise in popularity over the past two decades, with many of the landmark studies focusing on the efficacy of BFR on muscle strength and hypertrophy. ${ }^{4}$ The BFR, also known as Kaatsu training, involves decreasing blood flow to a muscle by applying a wrapping device, such as blood pressure cuff or restrictive straps. Kaatsu training restricts venous flow and induces the pooling of blood. Potential side effects, such as dizziness and fainting might occur. ${ }^{5,6}$

More recently, some papers have questioned the safety of BFR. ${ }^{5,6}$ The restrictive pressures range from 1.3 times higher than SBP $(\sim 160 \mathrm{mmHg})$ to beyond $200 \mathrm{mmHg}$. The width of the restrictive cuff influences the pressure applied. ${ }^{6}$ It should be noted that use of pressures (160-200 $\mathrm{mmHg}$ ) and tools may not provide enough acuity to personalize the level of occlusion to the limb. ${ }^{6}$ Another safety concern for some populations exposed to BFR exercise is that the occlusive conditions may promote the undesired coagulation at sites of vascular damage or atherosclerosis (ie, venous thromboembolism, peripheral vascular disease, blood clotting disorders, vascular endothelial dysfunction, and varicose veins). Because of these factors, exercise practitioners should consider intrinsic factors before implementing BFR. ${ }^{7}$ It is possible that the potential risks associated with BFR may explain why little is known on coagulation and fibrinolysis systems when exercising with BFR.

Virchow's triad predicts the causes of thrombus development: impaired blood coagulability (clotting factors elevation), changes in the vessel wall (loss of antithrombotic mechanisms), and stasis (immobility). ${ }^{8}$ While, blood fibrinolysis is designed to remove stable fibrin in a retracted clot due to the action of tPA, PAI-1 is the principal inhibitor of tPA. Subjects with hypofibrinolysis (ie, hypertension) experienced diminished tPA after resting and exercising arms with BFR using a manometer cuff at $100 \mathrm{mmHg}^{-1}$ for 10 minutes (to elicit venous occlusion). ${ }^{9}$ In addition, PAI-1 was significantly higher in patients with hypertension at rest when compared with control subjects. These findings were confirmed in patients with a history of idiopathic deep vein thrombosis after 10 and 20 minutes of venous occlusion, wherein PAI-1 was higher when compared with control subjects, and healthy subjects classified as non-responders or poor fibrinolytic response for tPA. ${ }^{10,11}$

With these noted hemostatic differences between patients and healthy subjects, it would be beneficial to understand the effects of BFR exercise on the coagulation system patients with risk for thromboembolic disorders and impaired fibrinolysis, such as hypertension, diabetes, and obesity. ${ }^{12-15}$ Knowing more about exercising BFR in diseased populations may improve safety when developing and implementing in exercise prescriptions.

BFR exercise may be performed with RT or walking. It has been shown that BFR positively influences bone metabolism, attenuates muscle strength loss, and minimizes atrophy in patients. Exercise with BFR also induces a comparable increase in muscle mass when compared with nonBFR, high-load RT. Implementing BFR is recommended to increase strength, while reducing loads on muscle, tendinous, connective and bone tissues for those who may be unable to perform high-intensity RT due to pain or damage to joint (knee osteoarthritis, those rehabilitating after injuries or surgery)..$^{4,16-18}$

Although the benefits of BFR exercise have been reported, it remains unclear whether pressurization of blood vessels causes thrombus formation by damaging the endothelial wall. Speculation for the risk of damage following BFR is supported by previous work. In the first human in vivo experiment, healthy young men underwent disturbed blood flow on the arm (promoted by pneumatic cuffs inflated to $200 \mathrm{mmHg}^{-1}$ ) during 20 minutes of rest. Findings indicated that acute BFR induced endothelial activation and apoptosis as reflected by the release of microparticles CD62E ${ }^{+}$and CD31 $1^{+} / \mathrm{CD} 42 \mathrm{~B} .{ }^{19}$ Synthesis of these data supports the close association between vascular occlusion and damage to the endothelium. ${ }^{19}$ With that, implementation of BFR may raise concern of irreparable endothelial damage and risk of thromboembolic disorders in subjects with pre-existing vascular dysfunction. However, low incidence of adverse effects (venous thrombus formation and pulmonary embolism) was reported after BFR exercise in healthy individuals. ${ }^{5}$

Other considerations may need to be made prior to implementing BFR with exercise in clinical populations. The prothrombotic tendency might be enhanced by the presence of peripheral artery occlusion disease (PAOD) and/or the progressive localized ischemia promoted by exercise. ${ }^{20} \mathrm{It}$ has been recorded that subjects with PAOD exhibit signs of abnormal upregulation of coagulation and fibrinolysis following a treadmill test. ${ }^{20}$ Furthermore, BFR exercise increases serum lactate and norepinephrine levels when compared with control sessions. ${ }^{21,22}$ Further, the presence of norepinephrine promotes the changes in hemostasis and fibrinolysis associated with exercise. ${ }^{20}$ With these known responses to exercise, 
it may not be advantageous for subjects at higher risk for thromboembolic disorders to be exposed to BFR.

The implementation of BFR exercise is rapidly growing in areas, such as professional sports and rehabilitation, as such, it is worthy to address these knowledge gaps through the systematic review of the effects of short- and long-term BFR exercise on blood hemostasis in healthy individuals and patients. ${ }^{23-25}$ This review attempted to verify the safety of BFR.

\section{Methods}

\section{Search strategy}

A systematic review was conducted according to recommendations from the PRISMA. ${ }^{26}$ The search strategies are reported below to ensure integrity of the results and allow for updates..$^{27,28}$ The Boolean and proximity operators were used and the search strategy was correctly adapted for each database listed in Table 1. Studies were identified by searching the following electronic databases: PubMED/MEDLINE (via National Library of Medicine; 2000 to 2018), Science Direct (Elsevier; 2000-2018), and Google Scholar (2000 to 2018). The last search was conducted in November 2018.

Once the abstracts were evaluated, full versions of the papers that met the criteria were obtained. In addition, the lists of references from papers that fulfilled the inclusion criteria were analyzed for the identification of additional undiscovered studies. The exclusion of studies with irrelevant content and duplicates were carried out in three steps (as described below). The title, abstract, and full-text articles were read by two reviewers (DCN and $\mathrm{BP}$ ). The reviewers assessed the eligibility of each study based on inclusion/exclusion criteria, and in case of disagreements, a third reviewer (JP) evaluated the article.

\section{Definition of terms}

The search terms used were as follows: "blood flowrestricted", "blood flow restriction", "Kaatsu training" associated with "fibrinolysis", "coagulation", "coagulation system", and "vascular endothelial function".

\section{Inclusion and exclusion criteria}

For the sake of clarity, we did not provide comparisons between BFR training with traditional RT or other exercise modalities without BFR. This evaluation was beyond the scope of this review as a body of evidence already exists about the effects of exercise and training on blood hemostasis in healthy individuals and patients..$^{1,2,29}$

The inclusion criteria were prepared according to the principle of PICOS (P: Participants; I: Intervention; $\mathrm{C}$ : Comparison; O: Outcomes; S: Study design). The details of

Table I Search strategies

\begin{tabular}{|c|c|c|c|}
\hline \multicolumn{4}{|c|}{ Search strategies and number of studies selected, by database } \\
\hline Database & Search strategy & Hits & $\begin{array}{l}\text { No. (\%) of trials } \\
\text { finally selected }\end{array}$ \\
\hline $\begin{array}{l}\text { PubMED/MEDLINE - via } \\
\text { National Library of Medicine } \\
\text { Articles that fulfil the } \\
\text { inclusion criteria }\end{array}$ & $\begin{array}{l}\text { "Blood flow-restricted" OR "Blood flow restriction" AND "Coagulation" } \\
\text { blood flow restriction AND haemosta* } \\
\text { Yasuda et al; }{ }^{34} \text { Clark et al; }{ }^{33} \text { Madarame et al:;8 Madarame et al }{ }^{39}\end{array}$ & $\begin{array}{l}5 \\
7\end{array}$ & 4 \\
\hline Science Direct (Elsevier) & "Blood flow-restricted" OR "Blood flow restriction" AND "Coagulation" & 9 & 0 \\
\hline Google Scholar & $\begin{array}{l}\text { "Blood flow-restricted" OR "Blood flow restriction" AND "Coagulation } \\
\text { system" AND "Fibrinolysis" } \\
\text { "Blood flow restriction" OR "Kaatsu training" AND "Vascular endothelial } \\
\text { function" } \\
\text { "Blood flow restriction" OR "Kaatsu training" AND "Coagulation } \\
\text { system" AND "Vascular endothelial function" } \\
\text { Yasuda et al; }{ }^{41} \text { Yasuda et al;;5 Shimizu et al }{ }^{36}\end{array}$ & $\begin{array}{l}19 \\
89 \\
9\end{array}$ & 3 \\
\hline $\begin{array}{l}\text { Additional records identified } \\
\text { through other sources } \\
\text { (reference list of the articles } \\
\text { that fulfil the inclusion criteria) }\end{array}$ & Fry et al $;{ }^{40}$ Nakajima et a ${ }^{37}$ & 2 & 2 \\
\hline Total & & 140 & 9 \\
\hline
\end{tabular}

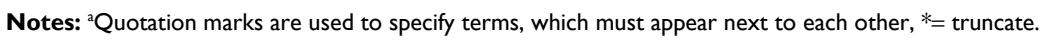


the inclusion criteria are explained as follows: 1) P: healthy individuals and patients (coronary heart disease, unstable hypertension, peripheral vascular disease, venous thromboembolism, hypercoagulable states, cardiopulmonary conditions, silent myocardial ischemia, hemophilia, individuals with musculoskeletal injury, diabetes, obesity, cancer, and those under medications that increase blood clotting risk) of any age; 2) I: the experimental group received exercise with BFR (ie, the use of any type of planned, structured, and repetitive movement paired with reduction of blood flow by a specially designed belt or cuffs); 3) C: conventional exercise training without BFR, or no-intervention control; 4) O: the primary outcomes were markers of thrombin generation (ie, prothrombin fragment 1+2), thrombin-antithrombin III complex), intravascular clot formation (ie, D-dimer, and fibrin degradation product [FDP]), parameters of vascular endothelial function, and endothelial cell damage (ie, von Willebrand factor [vWF]; and 5) S: randomized controlled trials (RCTs), and non-randomized controlled trials (NRCTs) as cohort and experimental studies in which individuals were assigned to different interventions using methods other than randomization.

In addition, only full-text articles citations with no restriction to language were included. The exclusion criteria were as follows: 1) meeting or conference abstracts, unpublished data, case reports, case series, letter to the editor, theses, or review articles; 2) the full text of the article was unavailable, despite making effort to contact the original authors.

\section{Data selection and analysis}

Two investigators (DCN and BP) analyzed the data and after removing duplicates, papers were screened for eligibility criteria. The search strategy is presented in Table 1. Then, quality assessment was evaluated independently by the investigators using the modified Downs and Black scale for the methodological quality assessment of both RCTs and NRCTs summarized in Table $2^{30}$

\section{Quality and levels of evidence assessment}

The quality assessment of eligible articles was evaluated using a modified version of Downs and Black checklist for assessing RCTs and NRCTs (consists of 27 questions). ${ }^{30}$ Items 1-10 refer to reporting, 11-13 refer to external validity, 14-26 refer to internal validity, and 27 relates to statistical power. Item 27 was modified based on whether the study presented a power calculation or not. Thus, the maximum score for item 27 was 1 (a power analysis was conducted) and 0 (a power analysis was not conducted). The highest score for

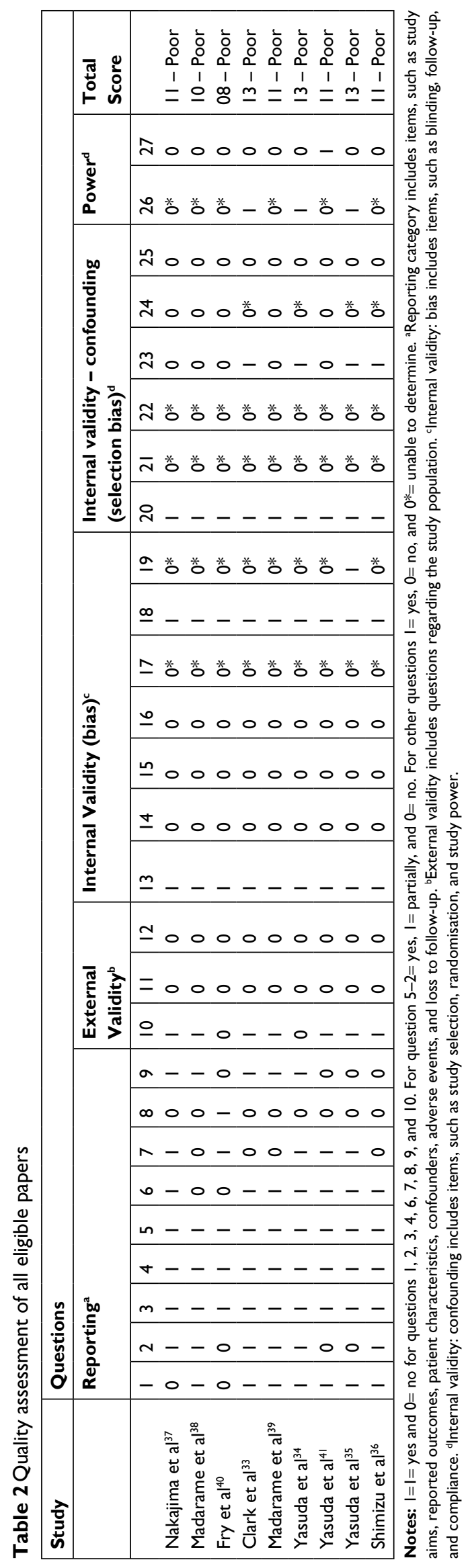


the checklist was 28 (instead of 32). Studies were classified as being excellent (26-28), good (20-25), fair (15-19), and poor $(\leq 14) .{ }^{31}$ Disagreements between authors were discussed and subsequently solved. The level of evidence of each article was determined according to the criteria described by the Oxford Center for Evidence-Based Medicine (OCEBM) and ranges between level $1 \mathrm{a}$ and $5 .^{32}$

\section{Results}

Among 140 papers thoroughly assessed, nine studies were included in the present review ( $\mathrm{RCTs}=4$ and NRCTs $=5) .{ }^{33-41}$ All studies reviewed contained significant methodological limitations, were classified as having poor methodological quality, failed to report the blinding procedures, and/or failed to report if there was compliance with the intervention. Intervention group sizes were too small and not representative of populations. The lack of power was a significant issue for most studies, yet only one addressed this deficiency. ${ }^{41}$ The most common issue was the failure to report possible adverse events that may be a consequence of BFR intervention. ${ }^{33-39,41}$ Another limitation was lack of RCTs (only four of the included nine), showing the absence of reported attrition rates (found in only three studies). ${ }^{33,33,34,34,35,35,36}$ A summary of the search results is presented in Figure 1.

\section{Intervention characteristics}

A total of 127 participants were included across the nine studies. One study included subjects with ischemic heart disease, while eight studies included young and apparently healthy older adults (age range between 23 and 72 years). ${ }^{33-41}$ In addition, only two studies reported the training history of participants; one study included those who were considered untrained and the other those considered physically active. ${ }^{37,40}$

The intensity of the exercise program was clearly described in seven of nine studies..$^{33,34,36-40}$ Two studies used elastic bands for RT combined with BFR. ${ }^{35,41}$ For the RT protocols with BFR, the intensity ranged between $20 \%$ and $30 \%$ of one-repetition maximum (1RM), with most (eight studies) standardizing RT for one set of 30 repetitions followed by three sets of 15 repetitions giving a rest interval between 30 and 90 seconds. ${ }^{33,34,36-39,41}$ The training programs ranged from 2 to 3 days per week for 4 to 12 weeks. ${ }^{33-36,41}$ A summary of the outcome measures are presented in Tables 3 and 4.

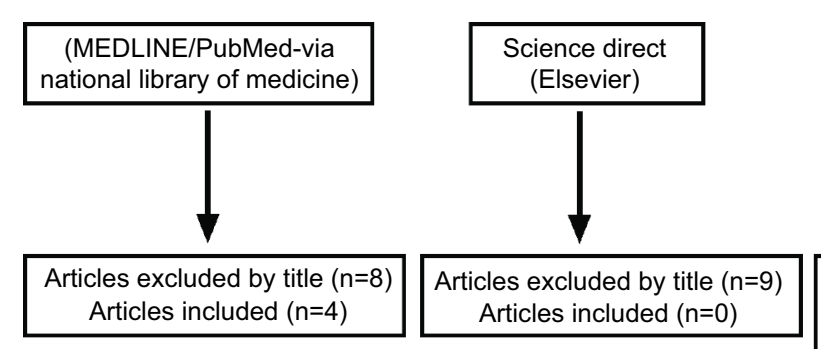

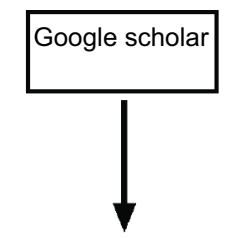

Articles excluded by titile $(n=100)$ Articles excluded by abstract $(n=5)$
Duplicated articles $(n=9)$ Articles included $(n=3)$

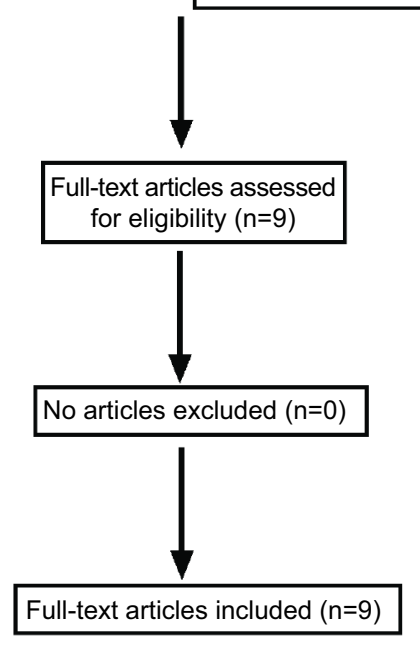

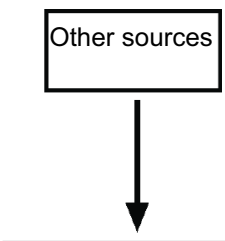

Articles included $(n=2)$
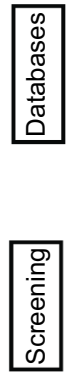

Figure I Summary of search results. 


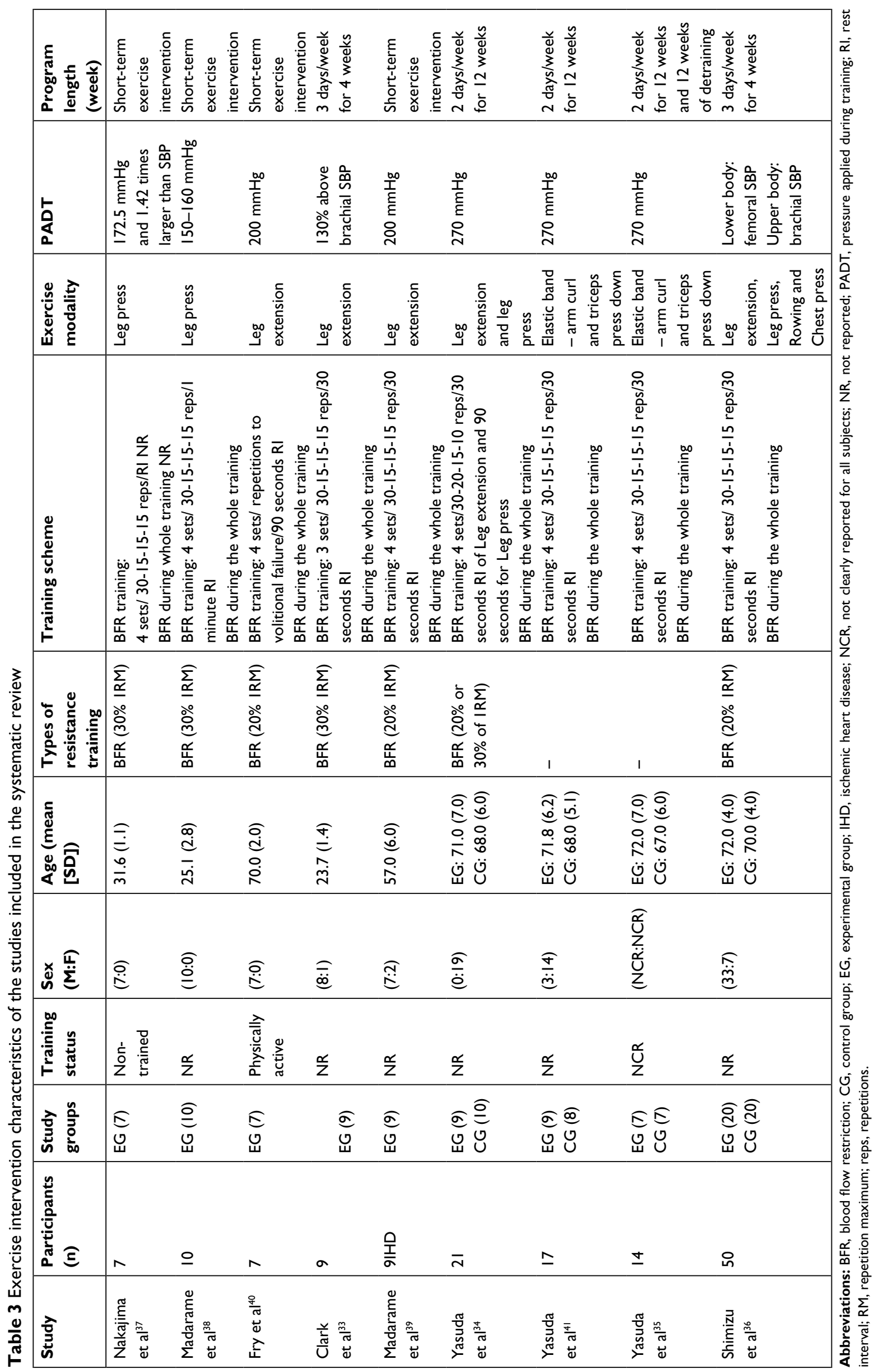


Table 4 Summary of outcome measures in the studies included in the systematic review

\begin{tabular}{|c|c|c|c|c|c|c|c|c|c|}
\hline \multirow[b]{2}{*}{ Study } & \multirow[b]{2}{*}{ Outcome } & \multicolumn{4}{|c|}{ EG (mean [95\% Cl or SD]) } & \multirow[b]{2}{*}{30 minutes } & \multirow[b]{2}{*}{$\begin{array}{l}\text { I hour } \\
\text { after }\end{array}$} & \multirow[b]{2}{*}{$\begin{array}{l}4 \text { hours } \\
\text { after }\end{array}$} & \multirow[b]{2}{*}{$\begin{array}{l}24 \text { hours } \\
\text { after }\end{array}$} \\
\hline & & Pre-exercise & Post-exercise & Detraining & 10 minutes & & & & \\
\hline $\begin{array}{l}\text { Nakajima } \\
\text { et } \mathrm{al}^{37}\end{array}$ & $\begin{array}{l}\text { tPA }(\mathrm{ng} / \mathrm{mL}) \\
\text { PAI-I }(\mathrm{ng} / \mathrm{mL}) \\
\text { PT }(\%) \\
\text { Fibrinogen }(\mathrm{mg} / \mathrm{dL}) \\
\text { FDP }(\mu \mathrm{g} / \mathrm{mL}) \\
\text { D-dimer }(\mu \mathrm{g} / \mathrm{mL}) \\
\text { Factor } 8(\%) \\
\text { Factor } 10(\%)\end{array}$ & $\begin{array}{l}2.1(0.1) \\
\text { NR } \\
82.3(2.7) \\
237.0(25) \\
2.0(0.0) \\
0.21(0.0) \\
\text { NR } \\
105.0(5.0)\end{array}$ & $\begin{array}{l}2.7(0.2) \uparrow \\
N R \leftrightarrow \\
86.4(3.0) \leftrightarrow \\
264.0(31.0) \leftrightarrow \\
2.1(0.1) \leftrightarrow \\
0.27(0.0) \leftrightarrow \\
N R \leftrightarrow \\
I 16.0(6.0) \leftrightarrow \\
\end{array}$ & & $\begin{array}{l}N R \leftrightarrow \\
N R \leftrightarrow \\
83.7(3.1) \leftrightarrow \\
239.0(28.0) \leftrightarrow \\
2.5(0.3) \leftrightarrow \\
0.25(0.0) \leftrightarrow \\
N R \leftrightarrow \\
I 08.0(5.0) \leftrightarrow \\
\end{array}$ & $\begin{array}{l}\mathrm{NR} \leftrightarrow \\
\mathrm{NR} \leftrightarrow \\
83.6(3.6) \leftrightarrow \\
235.0(26.0) \leftrightarrow \\
2.7 \mathrm{I}(0.57) \leftrightarrow \\
0.26(0.0) \leftrightarrow \\
\mathrm{NR} \leftrightarrow \\
\mathrm{I} 03.0(3.0) \leftrightarrow \\
\end{array}$ & & & \\
\hline $\begin{array}{l}\text { Madarame } \\
\text { et } \mathrm{al}^{38}\end{array}$ & $\begin{array}{l}\text { PTF }(\mathrm{pmol} / \mathrm{l}) \\
\text { TAT }(\mathrm{ng} / \mathrm{mL}) \\
\text { D-dimer }(\mu \mathrm{g} / \mathrm{mL}) \\
\text { FDP }(\mu \mathrm{g} / \mathrm{mL})\end{array}$ & & & & $\begin{array}{l}N R \leftrightarrow \\
N R \leftrightarrow \\
N R \leftrightarrow \\
N R \leftrightarrow \\
\end{array}$ & & $\begin{array}{l}\mathrm{NR} \leftrightarrow \\
\mathrm{NR} \leftrightarrow \\
\mathrm{NR} \leftrightarrow \\
\mathrm{NR} \leftrightarrow\end{array}$ & $\begin{array}{l}N R \leftrightarrow \\
N R \leftrightarrow \\
N R \leftrightarrow \\
N R \leftrightarrow \\
\end{array}$ & $\begin{array}{l}N R \leftrightarrow \\
N R \leftrightarrow \\
N R \leftrightarrow \\
N R \leftrightarrow \\
\end{array}$ \\
\hline Fry et $\mathrm{al}^{40}$ & D-dimer $(\mu g / m L)$ & $0.37(0.09)$ & $0.3(0.09) \leftrightarrow$ & & & & & & \\
\hline $\begin{array}{l}\text { Clark } \\
\text { et } \mathrm{al}^{33}\end{array}$ & $\begin{array}{l}\text { PT (INR) } \\
\text { tPA (ng/mL) } \\
\text { Fibrinogen }(\mathrm{ng} / \mathrm{mL}) \\
\text { D-dimer }(\mathrm{ng} / \mathrm{mL})\end{array}$ & $\begin{array}{l}\text { NR } \\
N R \\
N R \\
N R \\
\end{array}$ & $\begin{array}{l}N R \leftrightarrow \\
N R \leftrightarrow \\
N R \leftrightarrow \\
N R \leftrightarrow \\
\end{array}$ & & & & $\begin{array}{l}\mathrm{NR} \\
\mathrm{NR} \uparrow \\
\mathrm{NR} \\
\mathrm{NR} \\
\end{array}$ & & \\
\hline $\begin{array}{l}\text { Madarame } \\
\text { et a }\left.\right|^{39}\end{array}$ & D-dimer $(\mu \mathrm{g} / \mathrm{mL})$ & NR & $\mathrm{NR} \leftrightarrow$ & & & & $\mathrm{NR} \leftrightarrow$ & & \\
\hline $\begin{array}{l}\text { Yasuda } \\
\text { et } \mathrm{al}^{34}\end{array}$ & $\begin{array}{l}\text { FDP }\left(10^{-5} g / L\right) \\
\text { D-dimer }\left(10^{-5} g / L\right)\end{array}$ & $\begin{array}{l}2.9(I .1) \\
0.5(0.4)\end{array}$ & $\begin{array}{l}3.7(3.0) \leftrightarrow \\
1.2(1.6) \leftrightarrow\end{array}$ & & & & & & \\
\hline $\begin{array}{l}\text { Yasuda } \\
\text { et al }{ }^{41}\end{array}$ & $\begin{array}{l}\text { FDP }(\mu g / m L) \\
\text { D-dimer }(\mu g / m L)\end{array}$ & $\begin{array}{l}2.9(0.9) \\
0.2(0.1) \\
\end{array}$ & $\begin{array}{l}3.7(\mathrm{I} . \mathrm{I}) \leftrightarrow \\
0.3(0 . \mathrm{I}) \leftrightarrow \\
\end{array}$ & & & & & & \\
\hline $\begin{array}{l}\text { Yasuda } \\
\text { et al }{ }^{35}\end{array}$ & $\begin{array}{l}\text { FDP }(\mu g / m L) \\
\text { D-dimer }(\mu g / m L)\end{array}$ & $\begin{array}{l}2.9(0.9) \\
0.2(0.0) \\
\end{array}$ & $\begin{array}{l}3.3(1.0) \leftrightarrow \\
0.2(0.1) \leftrightarrow\end{array}$ & $\begin{array}{l}3.4(0.8) \leftrightarrow \\
0.2(0.15) \leftrightarrow\end{array}$ & & & & & \\
\hline $\begin{array}{l}\text { Shimizu } \\
\text { et } \mathbf{a l}^{36}\end{array}$ & $\begin{array}{l}\text { vWF (\%) } \\
\text { TM (U/mL) }\end{array}$ & $\begin{array}{l}\text { NR } \\
N R\end{array}$ & $\begin{array}{l}N R \downarrow \\
N R \leftrightarrow\end{array}$ & & & & & & \\
\hline
\end{tabular}

Abbreviations: EG, experimental group; FDP, fibrin degradation product; INR, international normalized ratio; NR, not reported; PT, prothrombin time; PTF, prothrombin fragment I+2; TAT, thrombin-antithrombin III complex; TM, thrombomodulin; TT, thrombin time; tPA, tissue plasminogen activator; PAI-I, plasminogen activator inhibitor-I; vWF, von Willebrand factor; $\downarrow$, decreased significantly; $\leftrightarrow$, no significant changes $\uparrow=$ increased significantly.

\section{Effects of short-term exercise with BFR on blood hemostasis}

A short-term intervention of BFR exercise increased the fibrinolytic activity assessed by tPA measures. ${ }^{37}$ In addition, data from this study suggested no changes in fibrin formation after leg press exercises with BFR. ${ }^{37}$

Short-term BFR exercise investigations with apparently healthy older men and middle-aged individuals with ischemic heart disease demonstrated that its implementation did not affect hemostatic nor intravascular clot formation. ${ }^{38-40}$ This suggests that acute BFR exercise may not exacerbate the activation of the coagulation system or enhance fibrinolytic activity in young healthy subjects. These data effectively support the safety of BFR implementation for participants described as young, middle-aged with stable ischemic heart disease, or apparently healthy older healthy subjects.

\section{Effects of long-term exercise with BFR on blood hemostasis}

Another study investigated the effects of 4 weeks of BFR exercise with low-load RT on prothrombin time, tPA, fibrinogen, and D-dimmer in healthy young individuals. The investigators found no longstanding significant effects, indicating that blood clotting function remained unchanged in healthy subjects. ${ }^{33}$ These findings were supported in another investigation reporting no adverse effects of BFR with low-load RT (BFR with elastic band) on FDP or D-dimmer in older, healthy subjects. ${ }^{34,35,41}$ Another intervention (4 weeks, low-load RT) demonstrated that vWF decreased significantly after BFR. Reduction in the vWF indicates improved vascular function in healthy older adults secondary to the BFR exercise. ${ }^{36}$ Together, these findings suggest that BFR exercise using low-load RT via elastic bands is a relatively safe method for older adults. 


\section{Discussion}

The purpose of this systematic review was to examine the safety along with short- and long-term effects of BFR exercise on blood hemostasis in healthy individuals and patients. To the best of our knowledge, this is the first systematic review of this nature and purpose. Overall, the findings presented demonstrate that short-term BFR exercise does not exacerbate the activation of the coagulation system nor enhance fibrinolytic activity in young healthy subjects. We posit that BFR would be relatively safe for adults considered young and healthy, those who are middle-aged with stable ischemic heart disease, and older healthy adults. Furthermore, data are available suggesting positive long-term effects of BFR exercise on coagulation factors.

However, it is difficult to definitively advocate the safety of BFR due to the state of the current literature. Most investigations fail to report adverse effects subsequent to BFR interventions. ${ }^{33}$ While not included in this review based on the inclusion and exclusion criteria, it is important to note that investigations do exist that report unintended responses, such as feeling cold, bruising, fainting, numbness, subcutaneous hemorrhage, and venous thrombus. ${ }^{5,42,43}$ Thus, future research should focus on attempting to measure and report side effects during and post BFR interventions.

It is important to note that the trainability of subjects was reported in only two of the nine included studies. ${ }^{37,40}$ There are significant implications concerning this issue, as enhanced fibrinolytic response to exercise differs according to training status of participants. ${ }^{2}$ Trained subjects present a higher tPA release following exercise when compared with untrained subjects, and a diminished fibrinolytic response has been noted in patients with myocardial ischemia. ${ }^{1,2}$ Thus, a clear report of trainability status should be required in future studies.

Another troubling concern was that the pressure applied during training ranged from 150 to $270 \mathrm{mmHg}$, using different occlusion methods, and different occlusion criteria (ie, $130 \%$ higher than SBP or same femoral and brachial SBP for lower and upper body). A study demonstrated that disturbed blood flow in the arm promoted by pneumatic cuffs inflated to $200 \mathrm{mmHg}^{-1}$ for 20 minutes induced acute endothelial activation and apoptosis as reflected by the release of microparticles as $\mathrm{CD} 62 \mathrm{E}^{+}$and $\mathrm{CD} 31^{+} / \mathrm{CD} 4 \mathrm{~B}^{-}$in healthy young men. Studies with BFR exercise should determine whether pressure applied during training would affect endothelial activation and apoptosis. ${ }^{19}$

The present systematic review consisted of four RCTs in young and older healthy subjects and five NRCTs, wherein one included adults with stable ischemic heart disease. ${ }^{33-41}$ This small sampling of available literature clearly demonstrates the need for more RCTs to adequately verify the safety of BFR exercise on blood hemostasis in subjects with increased risk for thromboembolic disorders, impaired fibrinolysis, diabetes, and obesity. ${ }^{12-15}$ Furthermore, $50 \%$ of the studies included were short-term interventions, thereby limiting the ability to detect the long-term responses in blood hemostasis to BFR.

Regarding research quality, the average score on the Downs and Black checklist was 11.22 (range 09-13), a less than desirable average. In addition, the level of evidence provided in the reviewed studies was level IIb (ie, poor quality randomized controlled studies). Further, the sample size of most studies was small. Another critical issue was the high prevalence of male subjects in the eligible studies. The underrepresentation of females might be influenced by the menstrual cycle or use of oral contraceptives potentially confounding the blood hemostasis analysis. Future studies with BFR exercise should include both sexes and determine whether sex difference affects the blood hemostasis response. ${ }^{44,45}$

A relevant issue in this systematic review was the standardized intensity ranging between $20 \%$ and $30 \%$ of $1 \mathrm{RM}$, the training scheme of 30 repetitions in the first set followed by three sets of 15 repetitions, and rest intervals ranging between 30 and 90 seconds. ${ }^{33,34,36-39,41}$ Keeping protocols similar in future studies (four sets of 30-15-15-15 repetitions and similar rest interval) should facilitate understanding how BFR exercise affects hemostasis.

The authors are cautioned not to provide any recommendation based on the OCEBM score of the available literature. Thus, practitioners must consider the evidence available and ask: 1) If the client is sufficiently similar to the subjects in the studies you have examined? 2) Does the treatment have a clinically relevant benefit that outweighs the potential risks? and 3) Is another treatment available that would provide greater results? ${ }^{46}$

If BFR exercise protocol cannot or should not be applied based on the potential risks factors, practitioners may prescribe RT at a load of $50 \%$ of $1 \mathrm{RM}$ at slow speed (3 seconds for lowering, 3 seconds for lifting, 1-second pause, and no relaxation phase). This scheme has shown to be adequate in generating intramuscular pressure that reduces the muscle's blood flow during training, without the application of external device. ${ }^{47,48}$ When in doubt, the use of traditional implementation of aerobic and RT might be the best option. ${ }^{1,2,29}$ 


\section{Conclusion}

Considering the limited available evidence, no firm recommendation can be made due to the weak methodological study designs. Furthermore, effort should be made to verify the effects of BFR exercise on hemostasis. The safety of BFR exercise on hemostasis must be explored in well-designed and improved methodological quality studies.

\section{Acknowledgments}

DCN would like to thank his family and, in particular, his mother Rita Cunha and son Nicolas Cunha. In addition, for English language editing, we thank Whitley J Stone from the Department of Nutrition and Kinesiology, University of Central Missouri, Warrensburg, MO, USA

\section{Author contributions}

All authors contributed to the study design, data collection, and article preparation; took part in drafting the article or revising it critically for important intellectual content; gave final approval of the version to be published; and agree to be accountable for all aspects of the work.

\section{Disclosure}

DCN received a Programa de Suporte à Pós-Graduação de Instituições de Ensino Particulares (PROSUP) grant from CAPES. JP received a productivity research grant from Coordenação de Aperfeiçoamento de Pessoal de Nível Superior (CNPQ). The authors report no other conflicts of interest in this work.

\section{References}

1. Nascimento DC, Neto FR, de Santana FS, da Silva RA, dos SantosNeto L, Balsamo S. The interactions between hemostasis and resistance training: a review. Int J Gen Med. 2012;5:249-254.

2. El-Sayed MS, El-Sayed Ali Z, Ahmadizad S. Exercise and training effects on blood haemostasis in health and disease: an update. Sports Med. 2004;34(3):181-200.

3. Dejong AT, Womack CJ, Perrine JA, Franklin BA. Hemostatic responses to resistance training in patients with coronary artery disease. $J$ Cardiopulm Rehabil. 2006;26(2):80-83.

4. Slysz J, Stultz J, Burr JF. The efficacy of blood flow restricted exercise: a systematic review \& meta-analysis. J Sci Med Sport. 2016;19(8):669-675.

5. Nakajima T, Kurano M, Iida $\mathrm{H}$, et al. Use and safety of KAATSU training: results of a national survey. Int J KAATSU Ttaining Res. 2006;2(1):5-13.

6. Loenneke JP, Wilson JM, Wilson GJ, Pujol TJ, Bemben MG. Potential safety issues with blood flow restriction training. Scand J Med Sci Sports. 2011;21(4):510-518.

7. Brandner CR, May AK, Clarkson MJ, Warmington SA. Reported sideeffects and safety considerations for the use of blood flow restriction during exercise in practice and research. Tech Orthop. 2018;33(2):114-121.

8. Esmon CT. Basic mechanisms and pathogenesis of venous thrombosis. Blood Rev. 2009;23(5):225-229.
9. Jansson JH, Johansson B, Boman K, Nilsson TK. Hypo-fibrinolysis in patients with hypertension and elevated cholesterol. J Intern Med. 1991;229(4):309-316.

10. Grimaudo V, Bachmann F, Hauert J, Christe MA, Kruithof EK. Hypofibrinolysis in patients with a history of idiopathic deep vein thrombosis and/or pulmonary embolism. Thromb Haemost. 1992;67(4):397-401.

11. Cugno M, Uziel L, Fabrizi I, Bottasso B, Maggiolini F, Agostoni A. Fibrinolytic response in normal subjects to venous occlusion and DDAVP infusion. Thromb Res. 1989;56(5):625-634.

12. Tabak O, Gelisgen R, Uzun H, et al. Hypertension and hemostatic/ fibrinolytic balance disorders. CIM. 2009;32(6):285.

13. Grant PJ. Diabetes mellitus as a prothrombotic condition. J Intern Med. 2007;262(2):157-172.

14. Mertens I, Gaal LFV, van Gaal LF, Obesity VGLF. Obesity, haemostasis and the fibrinolytic system. Obes Rev. 2002;3(2):85-101.

15. Landin K, Stigendal L, Eriksson E, et al. Abdominal obesity is associated with an impaired fibrinolytic activity and elevated plasminogen activator inhibitor-1. Metabolism. 1990;39(10):1044-1048.

16. Bittar ST, Pfeiffer PS, Santos HH, Cirilo-Sousa MS. Effects of blood flow restriction exercises on bone metabolism: a systematic review. Clin Physiol Funct Imaging. 2018;38(6):930-935.

17. Lixandrão ME, Ugrinowitsch C, Berton R, et al. Magnitude of muscle strength and mass adaptations between high-load resistance training versus low-load resistance training associated with blood-flow restriction: a systematic review and meta-analysis. Sports Med. 2018;48(2): 361-378.

18. Hughes L, Paton B, Rosenblatt B, Gissane C, Patterson SD. Blood flow restriction training in clinical musculoskeletal rehabilitation: a systematic review and meta-analysis. Br J Sports Med. 2017;51(13):1003-1011.

19. Jenkins NT, Padilla J, Boyle LJ, Credeur DP, Laughlin MH, Fadel PJ. Disturbed blood flow acutely induces activation and apoptosis of the human vascular endothelium. Hypertension. 2013;61(3):615-621.

20. Mustonen P, Lepäntalo M, Lassila R. Physical exertion induces thrombin formation and fibrin degradation in patients with peripheral atherosclerosis. Arterioscler Thromb Vasc Biol. 1998;18(2):244-249.

21. Takano H, Morita $\mathrm{T}$, Iida $\mathrm{H}$, et al. Hemodynamic and hormonal responses to a short-term low-intensity resistance exercise with the reduction of muscle blood flow. Eur J Appl Physiol. 2005;95(1):65-73.

22. Takano H, Morita T, Iida H, et al. Effects of low-intensity "KAATSU" resistance exercise on hemodynamic and growth hormone responses. Int $J$ KAATSU Ttaining Res. 2005;1(1):13-18.

23. Day B. Personalized blood flow restriction therapy: how, when and where can it accelerate rehabilitation after surgery? Arthroscopy. 2018;34(8):2511-2513.

24. Yow BG, Tennent DJ, Dowd TC, Loenneke JP, Owens JG. Blood flow restriction training after Achilles tendon rupture. J Foot Ankle Surg. 2018;57(3):635-638.

25. Ferraz RB, Gualano B, Rodrigues R, et al. Benefits of resistance training with blood flow restriction in knee osteoarthritis. Med Sci Sports Exerc. 2018;50(5):897-905.

26. Liberati A, Altman DG, Tetzlaff J, et al. The PRISMA statement for reporting systematic reviews and meta-analyses of studies that evaluate health care interventions: explanation and elaboration. J Clin Epidemiol. 2009;62(10):e1-e34.

27. Sampson M, Mcgowan J, Cogo E, Grimshaw J, Moher D, Lefebvre C. An evidence-based practice guideline for the peer review of electronic search strategies. J Clin Epidemiol. 2009;62(9):944-952.

28. Major MP, Major PW, Flores-Mir C. An evaluation of search and selection methods used in dental systematic reviews published in English. J Am Dent Assoc. 2006;137(9):1252-1257.

29. El-Sayed MS. Fibrinolytic and hemostatic parameter response after resistance exercise. Med Sci Sports Exerc. 1993;25(5):597???602-602.

30. Downs SH, Black N. The feasibility of creating a checklist for the assessment of the methodological quality both of randomised and nonrandomised studies of health care interventions. J Epidemiol Community Health. 1998;52(6):377-384. 
31. Hooper P, Jutai JW, Strong G, Russell-Minda E. Age-related macular degeneration and low-vision rehabilitation: a systematic review. Can J Ophthalmol. 2008;43(2):180-187.

32. Oxford. The 2011 Oxford CEBM levels of evidence. Available from: http://www.cebm.net.

33. Clark BC, Manini TM, Hoffman RL, et al. Relative safety of 4 weeks of blood flow-restricted resistance exercise in young, healthy adults. Scand J Med Sci Sports. 2011;21(5):653-662.

34. Yasuda T, Fukumura K, Fukuda T, et al. Muscle size and arterial stiffness after blood flow-restricted low-intensity resistance training in older adults. Scand J Med Sci Sports. 2014;24(5):799-806.

35. Yasuda T, Fukumura K, Iida H, Nakajima T. Effects of detraining after blood flow-restricted low-load elastic band training on muscle size and arterial stiffness in older women. Springerplus. 2015;4(1):348.

36. Shimizu R, Hotta K, Yamamoto S, et al. Low-intensity resistance training with blood flow restriction improves vascular endothelial function and peripheral blood circulation in healthy elderly people. Eur J Appl Physiol. 2016;116(4):749-757.

37. Nakajima T, Takano H, Kurano M, et al. Effects of KAATSU training on haemostasis in healthy subjects. Int $J$ KAATSU Ttaining Res. 2007;3(1):11-20.

38. Madarame H, Kurano M, Takano H, et al. Effects of low-intensity resistance exercise with blood flow restriction on coagulation system in healthy subjects. Clin Physiol Funct Imaging. 2010;30(3): 210-213.

39. Madarame H, Kurano M, Fukumura K, Fukuda T, Nakajima T. Haemostatic and inflammatory responses to blood flow-restricted exercise in patients with ischaemic heart disease: a pilot study. Clin Physiol Funct Imaging. 2013;33(1):11-17.
40. Fry CS, Glynn EL, Drummond MJ, et al. Blood flow restriction exercise stimulates mTORC1 signaling and muscle protein synthesis in older men. J Appl Physiol. 2010;108(5):1199-1209.

41. Yasuda T, Fukumura K, Uchida Y, et al. Effects of low-load, elastic band resistance training combined with blood flow restriction on muscle size and arterial stiffness in older adults. J Gerontol A Biol Sci Med Sci. 2015;70(8):950-958.

42. Yasuda T, Meguro M, Sato Y, Nakajima T. Use and safety of KAATSU training: results of a national survey in 2016. Int J KAATSU Ttaining Res. 2017;13(1):1-9.

43. Patterson SD, Brandner CR. The role of blood flow restriction training for Applied practitioners: a questionnaire-based survey. J Sports Sci. 2018;36(2):123-130.

44. Counts BR, Rossow LM, Mattocks KT, et al. Let's talk about sex: where are the young females in blood flow restriction research? Clin Physiol Funct Imaging. 2018;38(1):1-3.

45. Stegeman BH, de Bastos M, Rosendaal FR, et al. Different combined oral contraceptives and the risk of venous thrombosis: systematic review and network meta-analysis. BMJ. 2013;347(sep12 1):f5298.

46. Howick J, Chalmers I, Glasziou P, Greenhalgh T, Heneghan C, Liberati A. The Oxford CEBM levels of evidence (introductory document); 2011. Available from: https://www.cebm.net/2016/05/ ocebm-levels-of-evidence/.

47. Alberti G, Cavaggioni L, Silvaggi N, Caumo A, Garufi M. Resistance training with blood flow restriction using the modulation of the Muscle's contraction velocity. Strength Cond J. 2013;35(1):42-47.

48. Formenti D, Perpetuini D, Iodice P, et al. Effects of knee extension with different speeds of movement on muscle and cerebral oxygenation. PeerJ. 2018;6(3):e5704.
International Journal of General Medicine

\section{Publish your work in this journal}

The International Journal of General Medicine is an international, peer-reviewed open-access journal that focuses on general and internal medicine, pathogenesis, epidemiology, diagnosis, monitoring and treatment protocols. The journal is characterized by the rapid reporting of reviews, original research and clinical studies across all disease areas.

\section{Dovepress}

The manuscript management system is completely online and includes a very quick and fair peer-review system, which is all easy to use. Visit http://www.dovepress.com/testimonials.php to read real quotes from published authors. 